\title{
Interplay between baroreflex sensitivity, obesity and related cardiometabolic risk factors (Review)
}

\author{
SOFIA K. KONSTANTINIDOU ${ }^{1,2}$, GEORGIA ARGYRAKOPOULOU ${ }^{2}$, \\ NICHOLAS TENTOLOURIS ${ }^{1}$, VANGELIS KARALIS ${ }^{3}$ and ALEXANDER KOKKINOS ${ }^{1}$
}

${ }^{1}$ First Department of Propaedeutic Internal Medicine, School of Medicine, National and Kapodistrian University of Athens,
Laiko General Hospital, 11527 Athens; ${ }^{2}$ Diabetes and Obesity Unit, Athens Medical Center, 15125 Athens;
${ }^{3}$ Department of Pharmacy, School of Health Sciences, National and Kapodistrian University of Athens, 15784 Athens, Greece

Received September 25, 2021; Accepted November 3, 2021

DOI: $10.3892 / \mathrm{etm} .2021 .10990$

\begin{abstract}
The baroreflex represents a rapid negative feedback system implicated in blood pressure regulation, which aims to prevent blood pressure variations by regulating peripheral vascular tone and cardiac output. The aim of the present review was to highlight the association between baroreflex sensitivity (BRS) and obesity, including factors associated with obesity, such as metabolic syndrome, hypertension, cardiovascular disease and diabetes. For the present review, a literature search was conducted using the PubMed database until August 21, 2021. The searched terms included 'baroreflex', and other terms such as 'sensitivity', 'obesity', 'metabolic syndrome', 'hypertension', 'diabetes', 'gender', 'aging', 'children', 'adolescents', 'physical activity', 'bariatric surgery', 'autonomous nervous system' and 'cardiometabolic risk factors'. Obesity and its related metabolic disorders can influence baroreflex functionality and decrease BRS, mostly by potentiating sympathetic nervous system activity. Obesity induces inflammation, which can increase sympathetic system activity and lead to a higher incidence of cardiovascular events. Obesity also represents an important risk factor for hypertension through numerous mechanisms; in this setting, dysfunctional baroreceptors are not able to protect against constantly elevated blood pressure. Furthermore, diabetes mellitus and oxidative stress result in deterioration of BRS, whereas aging is also generally related to reduced cardiovagal
\end{abstract}

Correspondence to: Ms. Sofia K. Konstantinidou, First Department of Propaedeutic Internal Medicine, School of Medicine, National and Kapodistrian University of Athens, Laiko General Hospital, 17 Aghiou Thoma, 11527 Athens, Greece

E-mail: sofiakon@med.uoa.gr

Abbreviations: BMI, body mass index; BRS, baroreflex sensitivity; DM, diabetes mellitus; RYGB, Roux-en-Y gastric bypass; SG, sleeve gastrectomy; SNA, sympathetic nerve activity; T2DM, type II DM; WC, waist circumference

Key words: BRS, obesity, autonomic disorders, blood pressure regulation, metabolic syndrome
BRS. Differences in BRS have also been observed between men and women, and overall cardiovagal BRS in healthy women is less intense compared with that in men. BRS appears lower in children with obesity compared with that in children of a healthy weight. Notably, physical exercise can increase BRS in both hypertensive and normotensive subjects, and BRS can also be significantly improved following bariatric surgery and weight loss. In conclusion, obesity and its related metabolic disorders may influence baroreflex functionality and decrease BRS, and baroreceptors cannot protect against the constantly elevated blood pressure in obesity. However, following bariatric surgery and weight loss, BRS can be significantly improved. The present review summarizes the role of obesity and related metabolic risk factors in BRS, providing details on possible mechanisms and shedding light on their interplay leading to autonomic neuropathy.

\section{Contents}
1. Background
2. Methods
3. Obesity and metabolic syndrome
4. Obesity in children and adolescents
5. DM and insulin resistance
6. Hypertension
7. Physical activity
8. Sex differences
9. Aging
10. Baroreflex system and bariatric surgery
11. Conclusion

\section{Background}

The baroreflex represents a rapid negative feedback system, which serves an important role in blood pressure regulation, preventing blood pressure variations via its actions on peripheral vascular tone and cardiac output $(1,2)$. The sensor receptors, referred to as baroreceptors, are primarily located at the nerve endings of the carotid sinus and the aortic arch vessel wall (3). Dilatation of these sensors leads to increased 
vagal activity with a concomitant decrease in sympathetic nerve activity (SNA), whereas the opposite effect occurs when blood pressure decreases, achieving an overall blood pressure adjustment (4). Cardiac function is under the influence of both the sympathetic and parasympathetic systems, which modulate its electrophysiological properties, whereas the conduction system, ventricular myocytes, and the atrium and sinus nodes are also affected by the action of the autonomous system.

The effects of the baroreflex system on cardiac function are of paramount importance, particularly in stressful conditions. When blood pressure increases, the parasympathetic tone is enhanced and the sympathetic tone is suppressed, protecting the heart against arrhythmias (5); the opposite occurs when blood pressure decreases (Fig. 1). Therefore, the baroreflex system acts as a buffer system by adjusting blood pressure (4). The entire regulatory mechanism is known as baroreflex sensitivity (BRS).

In case of baroreflex failure, the volume load tolerance is impaired and may lead to several serious clinical manifestations, including pulmonary edema $(1,6)$. Heart failure with reduced left ventricular ejection fraction and left ventricular diastolic dysfunction are also induced by baroreflex failure (6). In the presence of baroreflex dysfunction, risk factors such as diabetes mellitus (DM), renal insufficiency, aging, atherosclerosis and hypertension become even more important for the development of heart failure (7). Notably, prenatal hypoxia leading to baroreflex failure may result in adult hypertension (8).

In mathematical terms, BRS can be defined as the ratio of inter-beat interval change (in $\mathrm{msec}$ ) over the unit change of blood pressure (5). Namely, when inter-beat interval increases by $100 \mathrm{msec}$ and blood pressure rises by $10 \mathrm{mmHg}$, the BRS is equal to $100 / 10$, which is referred to as $10 \mathrm{msec} / \mathrm{mmHg}$. With regard to the aforementioned example, the increase in inter-beat interval can result from either an increase in parasympathetic tone, or from a decrease in sympathetic tone. It has been demonstrated that the joint influence of the sympathetic and vagal systems on the sinus node contributes to the actual heart rate. Besides, blood pressure fluctuations are buffered by the baroreflex system, mainly by adjusting peripheral resistance (9). In case of changes in blood pressure, a short time lag is required for baroreflex control system actions to take effect towards resistance adjustments (5). Like most negative feedback systems, the baroreflex exerts a periodic performance with a period close to $10 \mathrm{sec}$.

The measurement of BRS is considered a valuable tool for the evaluation of numerous cardiovascular diseases (10). BRS measurements focus on the ability of the autonomous system to react to blood pressure changes at the aortic arch and carotid sinus (11). Cardiovascular tests and analysis of heart rate variability (HRV) can be used for the diagnosis of autonomic neuropathy, in which the nerves that control involuntary bodily functions are damaged (12). In addition, the non-invasive volume-clamp method allows for quantification of the neural modulation of the sinus node mediated by arterial baroreceptors (13).

Several methods have been proposed for measurement of BRS (Fig. 2) (14), for example using vasoactive drugs (such as phenylephrine) to increase blood pressure, which suppresses heart rate and subsequently increases the inter-beat interval (5). The 'neck chamber technique' is another method where a positive/negative pressure is applied to the neck, leading to deactivation of carotid baroreceptors (14). During the Valsalva maneuver, a breathing method used in the diagnosis of autonomic nervous system dysfunction, increased abdominal and intrathoracic pressure triggers activation of baroreceptors. The 'sequence method' is another approach for the quantification of BRS, which is based on the application of linear regression analysis between decreasing/increasing blood pressure and changes in the R-R interval, namely, the time between two successive R-waves of the QRS signal of the electrocardiogram (15). Other techniques rely on carotid ultrasound imaging, such as measurement of the change in the diameter of the carotid artery after alteration in arterial pressure (15). Alternatively, the change in R-R interval (cardiac baroreflex) or muscle SNA (sympathetic baroreflex) can be measured as a result of barosensory vessel stretch. Also, several algorithms in time and frequency domain (when Fast Fourier transform is applied to convert the signal from time to frequency domain) have been proposed for the non-invasive measurement of BRS (14), which quantify BRS based on the association between periodic sequences of the two signals, specifically inter-beat interval and blood pressure.

BRS is an important homeostatic system the function of which can be influenced by several risk factors (16). Obesity can markedly decrease BRS, and can lead to sympathovagal imbalance by decreasing parasympathetic activity and increasing SNA (17). Notably, high abdominal visceral fat has been shown to reduce BRS compared with in patients with lower total and abdominal fat (18). Similarly, randomized clinical trials have shown that accompanying features of obesity, such as hyperinsulinemia, insulin resistance and hypoadiponectinemia, decrease BRS (17). In addition, the adoption of a hypocaloric diet has been shown to lead to improvement of BRS in patients with obesity (19). Furthermore, hypoadiponectinemia in patients with type II DM (T2DM) has been related to reduced BRS (20). Other factors significantly linked to reduced BRS include atherosclerosis (21) and aging (22). In addition, dyslipidemia has been reported to constitute a risk factor that is negatively correlated with the functionality of the baroreflex system (22).

Specific treatments for improving BRS and subsequent variations in blood pressure are not currently available (1). A clinical study showed that angiotensin-converting enzyme inhibitors may provide an improvement in patients with hypertension (23). Furthermore, a previous animal study demonstrated that $\beta$-blockers can attenuate short-term variability in blood pressure, and treatment with L-arginine was able to restore depressed BRS (24). Another study tested non-pharmacological treatment methods, such as vagal afferent nerve activation, which was reported to improve BRS functionality and reverse blood pressure variability (25).

The aim of the present review was to highlight the relationship between BRS and obesity, including factors closely associated with obesity, such as the metabolic syndrome, hypertension, cardiovascular disease and DM. A specific emphasis has been placed on the role of aging and sex differences, the impact of exercise and training, as well as changes in BRS in patients with obesity following bariatric surgery. 


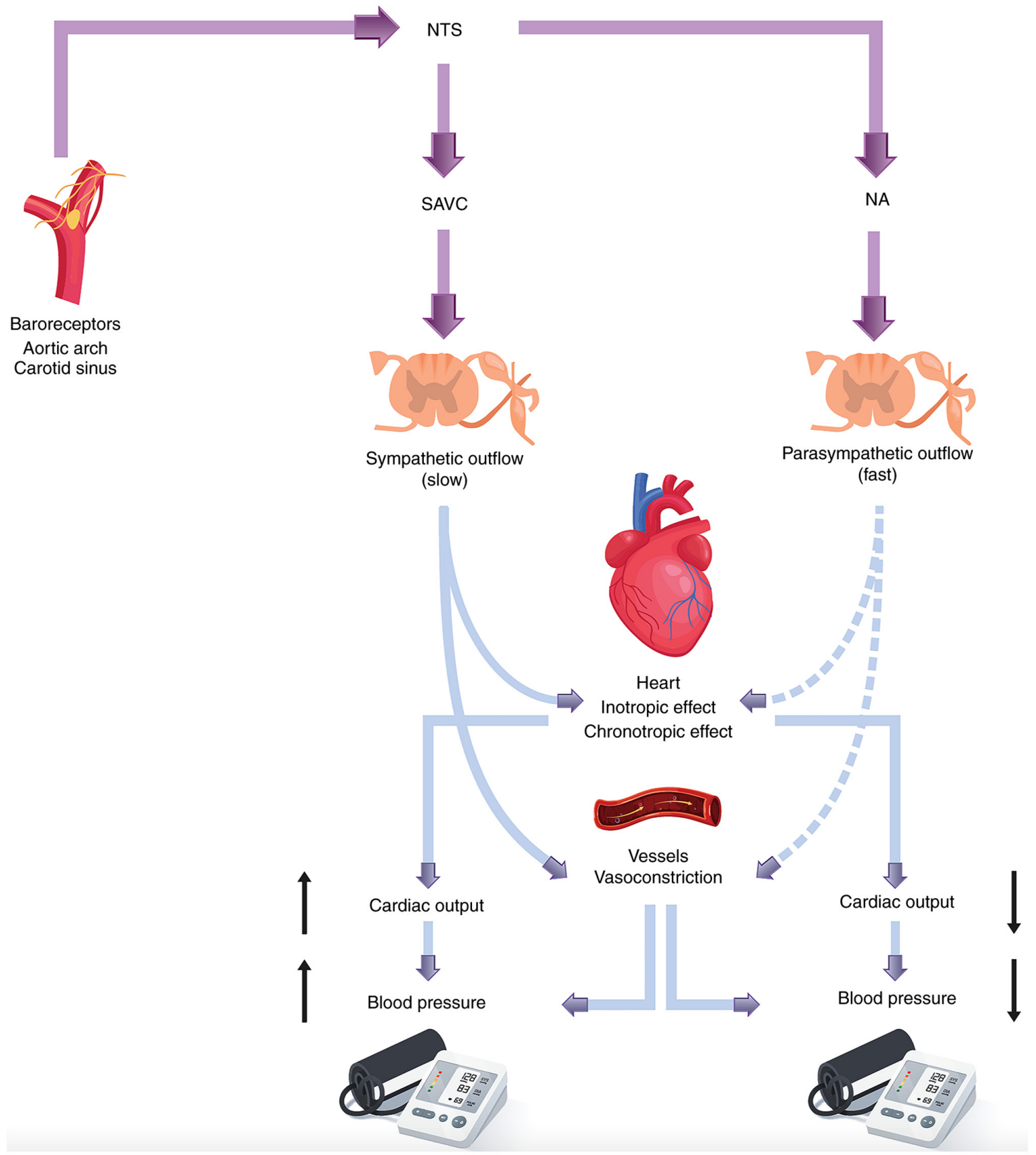

Figure 1. Interrelation between blood pressure variations, baroreceptors and brainstem regulation. Continuous lines indicate stimulation; dashed lines indicate inhibition. NTS, nucleus tractus solitarius; SAVC, sympathetic adrenergic vasomotor center; NA, nucleus ambiguus.

\section{Methods}

Search strategy. A literature search was conducted using the PubMed database (pubmed.ncbi.nlm.nih.gov) from January 14, 2021 until August 21, 2021. The searched terms were: 'baroreflex' + 'sensitivity', 'baroreflex' + 'obesity', 'baroreflex: + 'metabolic syndrome', 'baroreflex' + 'hypertension', 'baroreflex' + 'diabetes', 'baroreflex' + 'gender', 'baroreflex' + 'aging', 'baroreflex' + 'children' + 'adolescents', 'baroreflex' + 'physical activity', 'baroreflex' + 'bariatric surgery', 'autonomous nervous system' + 'regulation' and 'baroreflex sensitivity' + 'cardiometabolic risk factors'. The search strategy results are presented in Table I and a schematic representation of the route of selection is shown in Fig. 3.
Selection criteria. After removing duplicate articles, the authors evaluated all studies based on the following criteria: i) Journal, ii) authorship, iii) publication date, iv) study design, v) methods of analysis, vi) results, and vii) conclusions. The eligibility criteria were as follows: Articles written in English, which were relevant to the objective of the review, and the absence of confounding diseases. One of the authors reviewed the abstracts of each identified study and excluded them if they did not meet the eligibility criteria. In order to improve data quality, all studies that met the inclusion criteria were thoroughly evaluated in terms of rationale, method design, primary outcome, fatigue assessment, statistical analysis, results, discussion and conclusions. Those studies that displayed any bias in the methodology, results or interpretation of the data, 
A

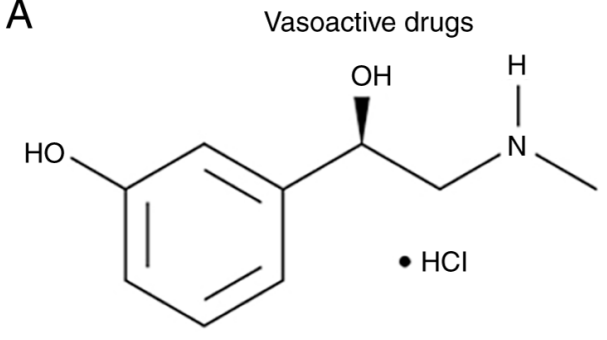

B

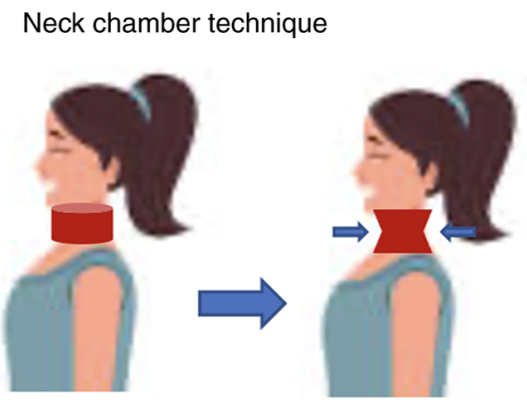

C

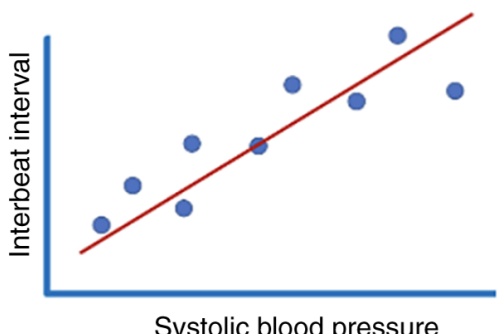

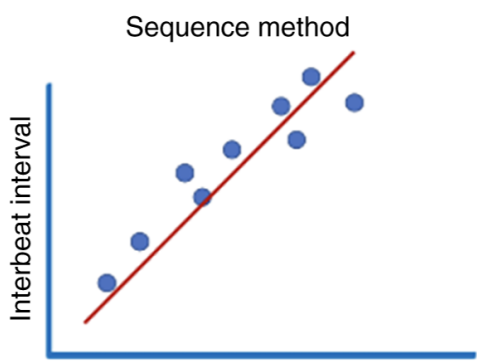

Systolic blood pressure

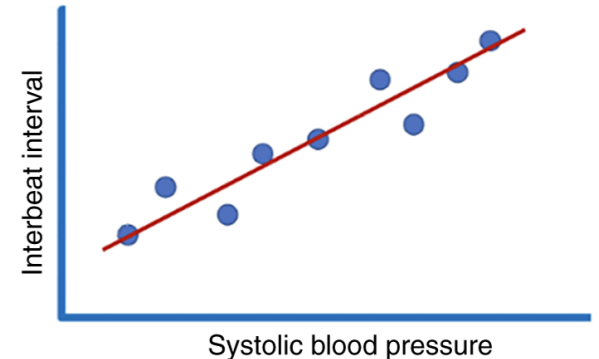

Figure 2. Three popular methods for measuring baroreflex sensitivity. (A) The use of vasoactive drugs, such as phenylephrine, to increase blood pressure and reduce heart rate, so as to increase the inter-beat interval. (B) Neck chamber technique. (C) Sequence method.

which could be reflected in the overall analysis of the study, were also excluded (Fig. 3). Finally, 102 articles were selected for inclusion.

\section{Obesity and metabolic syndrome}

Obesity represents a chronic relapsing disease comprising important concurrent metabolic and clinical disorders, such as DM, dyslipidemia, cardiovascular disease, sleep apnea and autonomic neuropathy, when the nerves controlling involuntary body functions are destroyed. It can impact blood pressure, temperature regulation, digestion and bladder and sexual function (26). Overall, it is associated with potentiation of the sympathetic nervous system (27). Previously, clinical studies have identified an association between autonomic nervous system regulation and obesity $(28,29)$. Notably, it has been shown that as body weight increases, baroreflex function is significantly suppressed (28). Furthermore, the guidelines of the European Society of Hypertension and the European Society of Cardiology have underlined the role of waist circumference (WC) in BRS (30,31). A direct association between BRS and fat mass distribution has been demonstrated in hypertensive populations, where central obesity led to impaired BRS. Thus, in patients with central obesity, the enhanced sympathetic cardiovascular effort may be added to the metabolic risk factors, such as dyslipidemia, elevated blood pressure and elevated plasma glucose, which can lead to an increased risk for cardiovascular complications.

Obesity may contribute to the process of carotid atherosclerosis via multiple pathogenetic mechanisms, including carotid media thickening and hyperleptinemia (3). A decrease in BRS has been reported to be associated with carotid intima media thickness; therefore, it was hypothesized that obesity-related atherosclerosis may lead to changes in baroreceptor signaling, which in turn could increase sympathetic activity and decrease BRS (3). In addition, hormonal factors that are implicated in the complex biological pathways of long-term maintenance of body weight and energy balance seem to play a role in the association between obesity and BRS (32). Leptin is a fundamental hormone that is secreted primarily by adipose cells and acts as a marker of total body energy reflecting adipose tissue mass (3). In the obese state, neurons located at hypothalamic nuclei that express leptin receptors are desensitized as a result of chronically elevated leptin levels; thus, the anorexigenic effect of leptin is suppressed (33). Leptin can also exert its action at the level of the nucleus of the solitary tract, affecting neurons important to BRS (34). Leptin has previously been reported to act as a critical signal in activation of the renal sympathetic nerve by activating the brain renin-angiotensin system, hypothalamic phosphatidylinositol 3-kinase and melanocortin receptors $(3,35)$. Leptin receptors also serve an important role in leptin-induced renal sympathetic nerve activation; the knockout of leptin receptors in the hypothalamus has been shown to hinder the activation of sympathetic nerves in patients with obesity and hypertension (3).

It is known that central obesity and visceral fat can lead to increased activation of the sympathetic nervous system compared with peripheral obesity $(18,36)$. This finding suggests that central obesity is characterized by autonomic imbalance with hyperactivity of the sympathetic nervous system. In this context, a previous study aimed to analyze the relationship between abdominal fat distribution (measured by WC) and vagal tone (as expressed by spontaneous BRS) (30). The results demonstrated that the impairment in BRS was greater in patients with central obesity compared with in those with peripheral adipose distribution. Thus, the higher risk for cardiovascular complications observed in patients with central obesity may not only be ascribed to metabolic factors, but also to the activated sympathetic nervous system. Fat distribution 
Table I. Literature search strategy results from PubMed.

\begin{tabular}{lrr}
\hline Search terms & $\begin{array}{c}\text { Citations retrieved } \\
\text { (August 21, 2021) }\end{array}$ & $\begin{array}{r}\text { Studies retrieved after } \\
\text { screening of title and abstract }\end{array}$ \\
\hline 'baroreflex' + 'sensitivity' & 4,571 & 98 \\
'baroreflex' + 'obesity' & 257 & 35 \\
'baroreflex + 'metabolic syndrome' & 87 & 18 \\
'baroreflex' + 'hypertension' & 3,149 & 112 \\
'baroreflex' + 'diabetes' & 502 & 87 \\
'baroreflex' + 'gender' & 494 & 46 \\
'baroreflex' + 'aging' & 498 & 37 \\
'baroreflex' + 'children' + 'adolescents' & 117 & 22 \\
'baroreflex' + 'physical activity' & 1,484 & 23 \\
'baroreflex' + 'bariatric surgery' & 8 & 6 \\
'autonomous nervous system'+ 'regulation' & 2,401 & 64 \\
'baroreflex sensitivity' + 'cardiometabolic risk factors' & 9
\end{tabular}

may also serve an important role in the autonomic balance and the development of hypertension (30).

The relationship between obesity, BRS and cardiovascular diseases was further investigated by including the role of immune system in the exploration (37). It has been hypothesized that there is a 'triangle' between autonomic regulation (including BRS), cardiovascular diseases (e.g., hypertension, heart failure) and the immune system. The impact of the autonomic system on cardiovascular pathology has also been thoroughly studied; sympathetic activation and parasympathetic suppression has been revealed to worsen heart failure or hypertension, and subsequently increase morbidity and mortality (37).

The end-organ damage in hypertension or heart failure can be worsened or alleviated by pro- or anti-inflammatory pathways of the immune system, respectively, which are triggered by neurohumoral transmitters (37). The strong association between inflammation and obesity has resulted in studies that aim to unveil the link between obesity-induced inflammation and other diseases $(26,38)$. Inflammation is induced by obesity as a result of a chronically mediated immune response, which is accompanied by the secretion of cytokines, acute phase proteins (e.g., C-reactive protein) and chemokines (38). In turn, acute or chronic inflammation increases the activity of the sympathetic system, leading to an increased incidence of cardiovascular events (39). Notably, a previous study was conducted examining the potential beneficial effects of administering non-steroidal anti-inflammatory drugs (e.g., ibuprofen) to individuals with obesity in order to adjust their BRS (10); however, an acute dose of ibuprofen did not exert an effect on BRS.

The importance of studying the role of obesity in the baroreflex system is reflected in the large number of clinical trials either ongoing or recently completed (Table II). Since central obesity is one of the primary risk factors for metabolic syndrome, research has focused on the association between obesity and aspects of metabolic syndrome (40-46).

Metabolic syndrome is a term strongly associated with obesity. It is used to describe a cluster of related metabolic abnormalities, namely obesity, dyslipidemia, hypertension and glucose intolerance, which lead to an increased risk of cardiovascular morbidity and mortality (47). Several definitions of metabolic syndrome have been provided; however, the term is typically used to characterize the condition when at least three of the following situations are present: Increased WC, low high-density lipoprotein levels, increased triglycerides in the blood, elevated fasting glucose levels and hypertension (47). A common pathogenetic characteristic in all these conditions is activation of the sympathetic nervous system (48). Several pathophysiological mechanisms are responsible for central sympathetic overactivity in patients with metabolic syndrome (32) and these neurogenic alterations may be attributed to impairment of BRS (49). Notably, a previous study observed an impairment of baroreceptor control in patients with metabolic syndrome (49). Other reflexogenic areas, such as the cardiopulmonary receptors and chemoreceptors, may also exert a role in baroreflex alterations (49). Notably, this finding was observed in patients with obesity and sleep apnea, and hypertensive patients with left ventricular hypertrophy who showed impairment of BRS (50).

A previous study in 2,835 patients aged 50 to 75 years old evaluated the hypothesis as to whether metabolic syndrome is associated with the BRS pathway (51). According to this study, patients with metabolic syndrome had lower neural baroreflex pathway (NBP). The processes linking carotid artery stiffness and NBP were inactive in patients with metabolic syndrome, regardless of blood pressure levels. One study compared arterial baroreflex-deficient rats and normal rats with BRS differences of 2.5 -fold (52); this study found that an intrinsically low BRS caused hypertension and metabolic disorder. Restoration of defective BRS could be an effective target for therapeutic intervention in metabolic syndrome

\section{Obesity in children and adolescents.}

There has recently been an increased interest in studying BRS in children, examining its relationship with obesity and its role for the future development of hypertension. Obesity in 


\section{Identification of studies via PubMed}

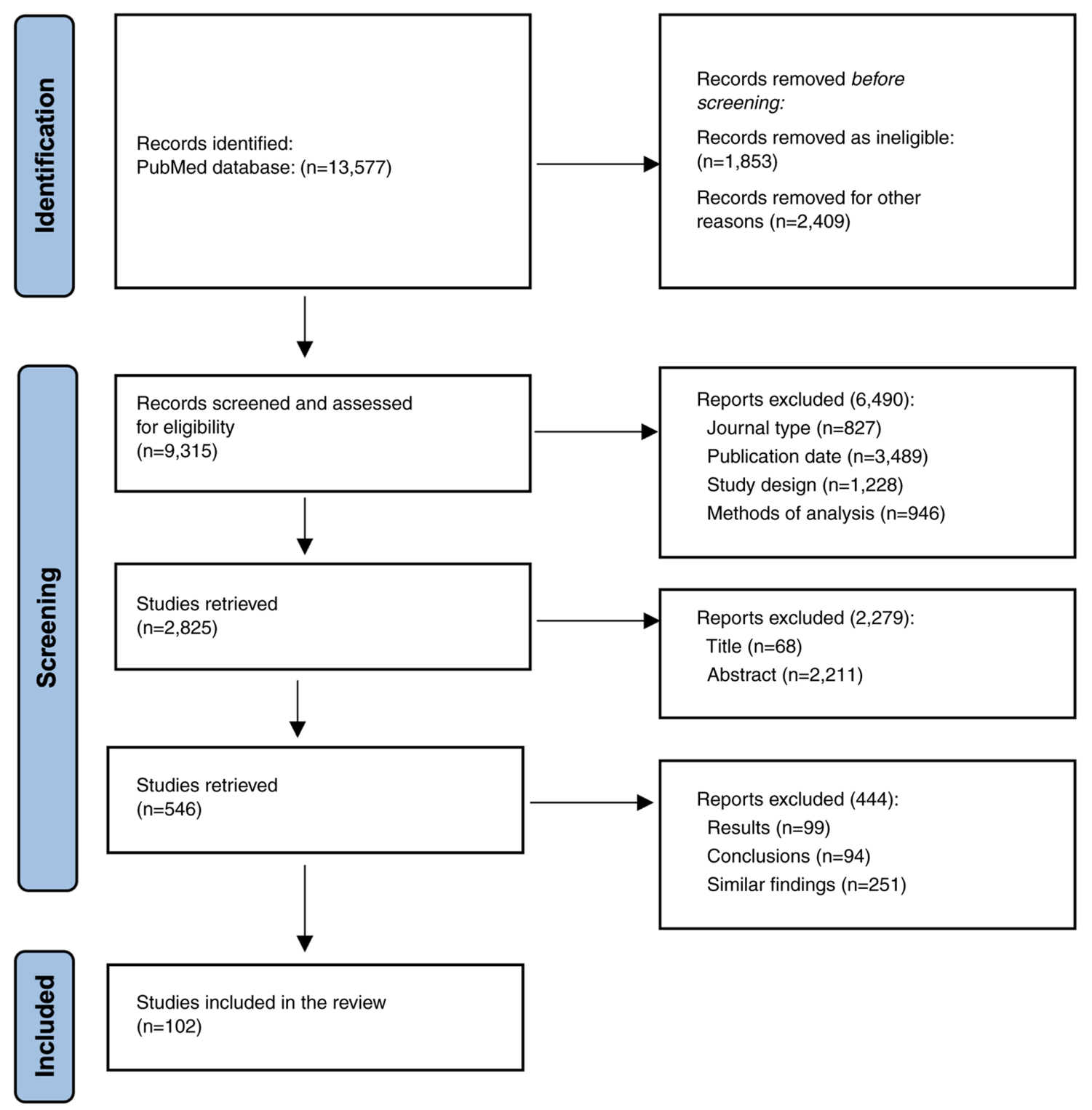

Figure 3. Schematic representation of the selection route of the studies analyzed in the present review.

childhood is associated with hypertension in adulthood (53). A previous study was performed in 20 children and adolescents with obesity, who were compared with sex- and age-matched control individuals of a healthy weight (54). BRS was found to be significantly lower in individuals in the obese range compared with in children of a healthy weight. In addition, relying on the instantaneous heart rate measurement of BRS, a statistically significant reduction in BRS (between obese and healthy weight individuals) was observed in subjects between 11 and 20 years. Another study analyzed BRS in normotensive adolescents and children using two different measurement techniques: Causal and non-causal BRS methods (55). Causal methods allow the separation of feedforward and feedback variations; by using causal analysis it is possible to separate both causal directions of the system, namely variations within the SBP induced by HR and vice versa. According to the non-causal BRS method, no significant differences were found between children and adolescents; however, the causal BRS method identified significantly lower BRS values in children in the obese range compared with normal weight children (55).

The relationship between body weight, BRS and blood pressure variability was also assessed in a study by Honzíková et al (56). In this analysis, an increased body mass index (BMI) in children, adolescents and young adults was associated with suppression of BRS and hypertension. The greater the increase in BMI, the deeper the BRS reduction, the higher the hypertension and the more increased variability in systolic blood pressure.

A genetic dependency of BRS was identified in another study (53). Baroreflex sensitivity is decreased in young normotensive individuals whose parents have hypertension compared with individuals without a family history of hypertension. In addition, associations between several gene polymorphisms and baroreflex heart rate regulation have been described. Reduced 


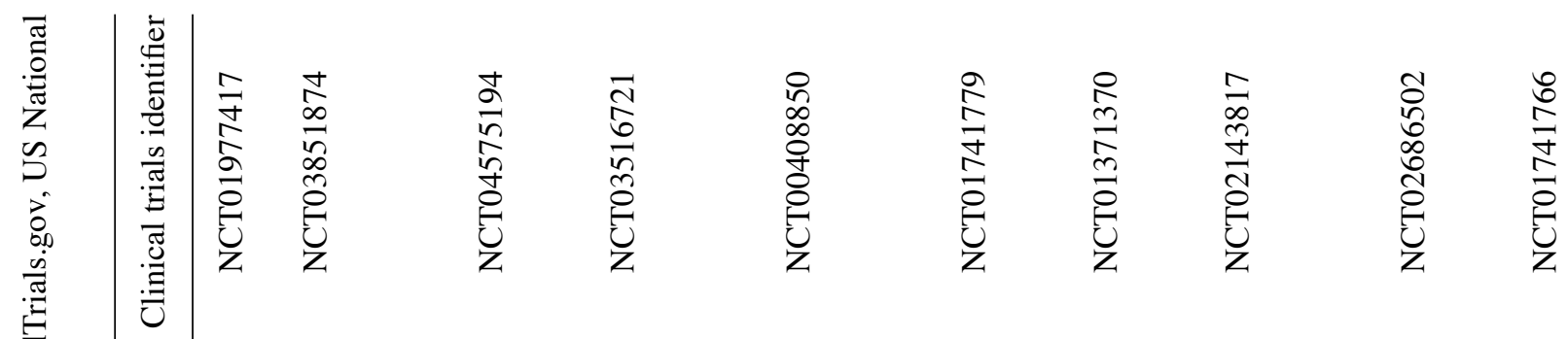
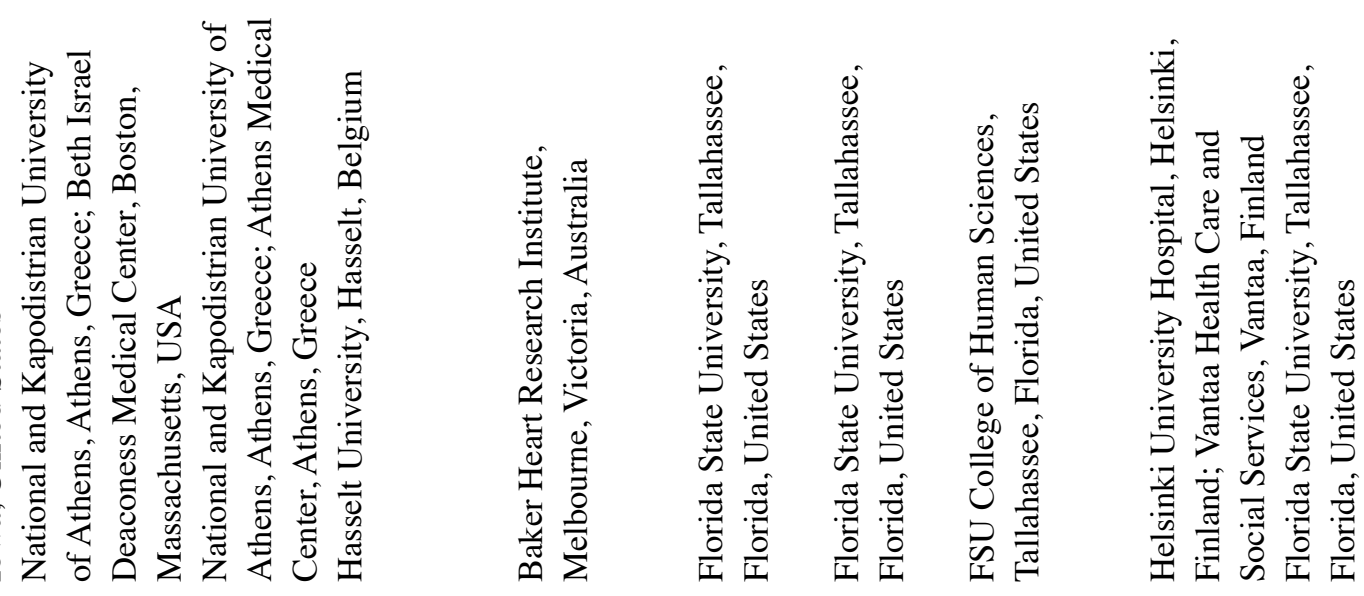

章

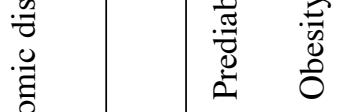

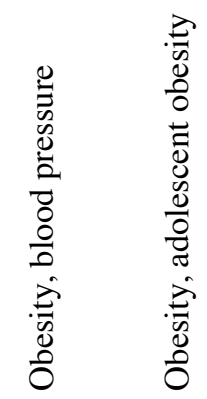

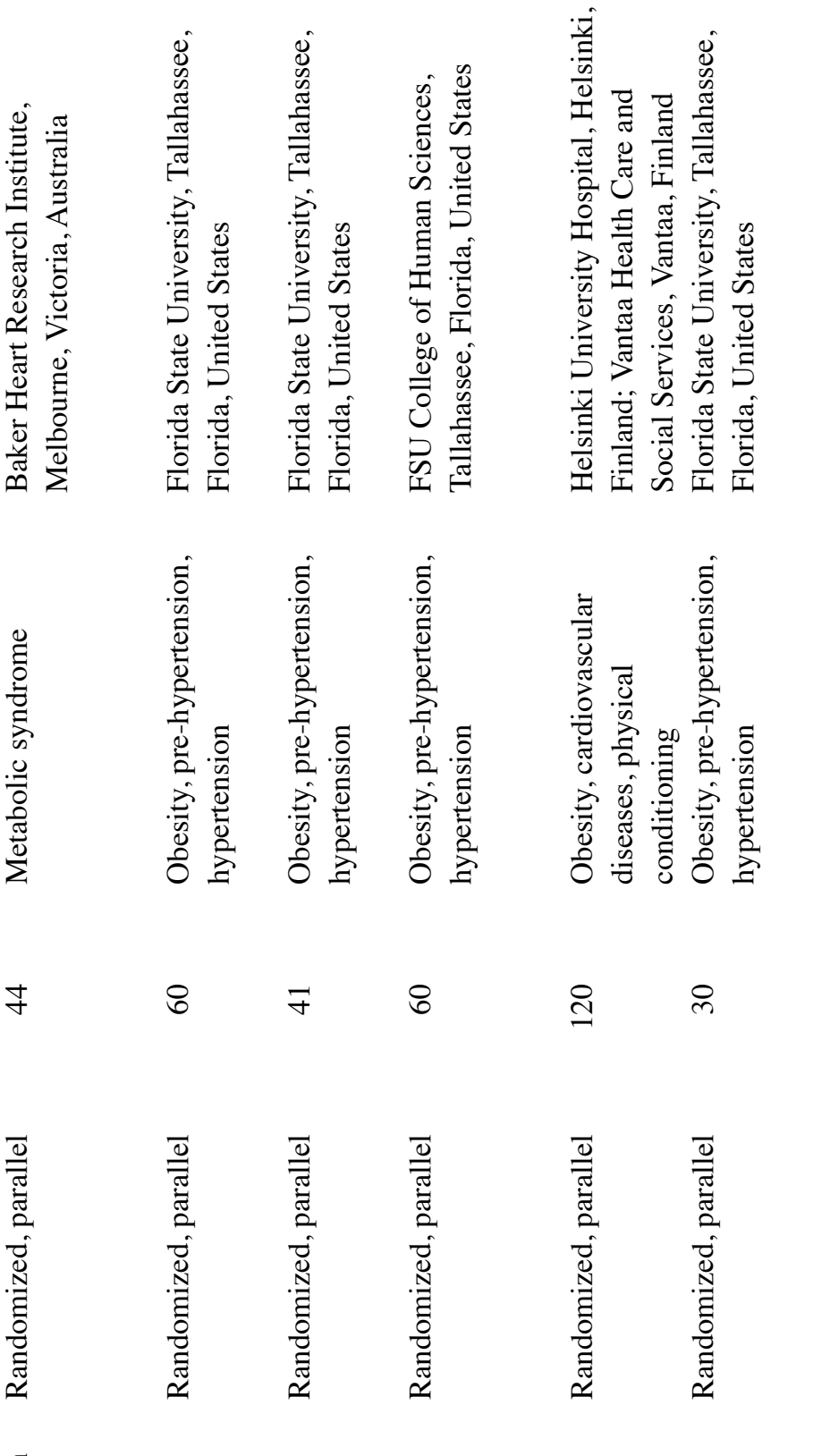

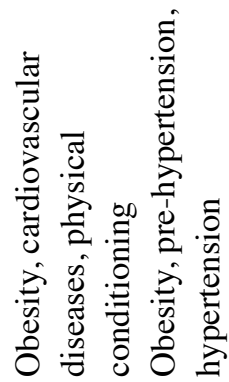

疍

ส

?:

ญี

递

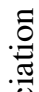

.

.



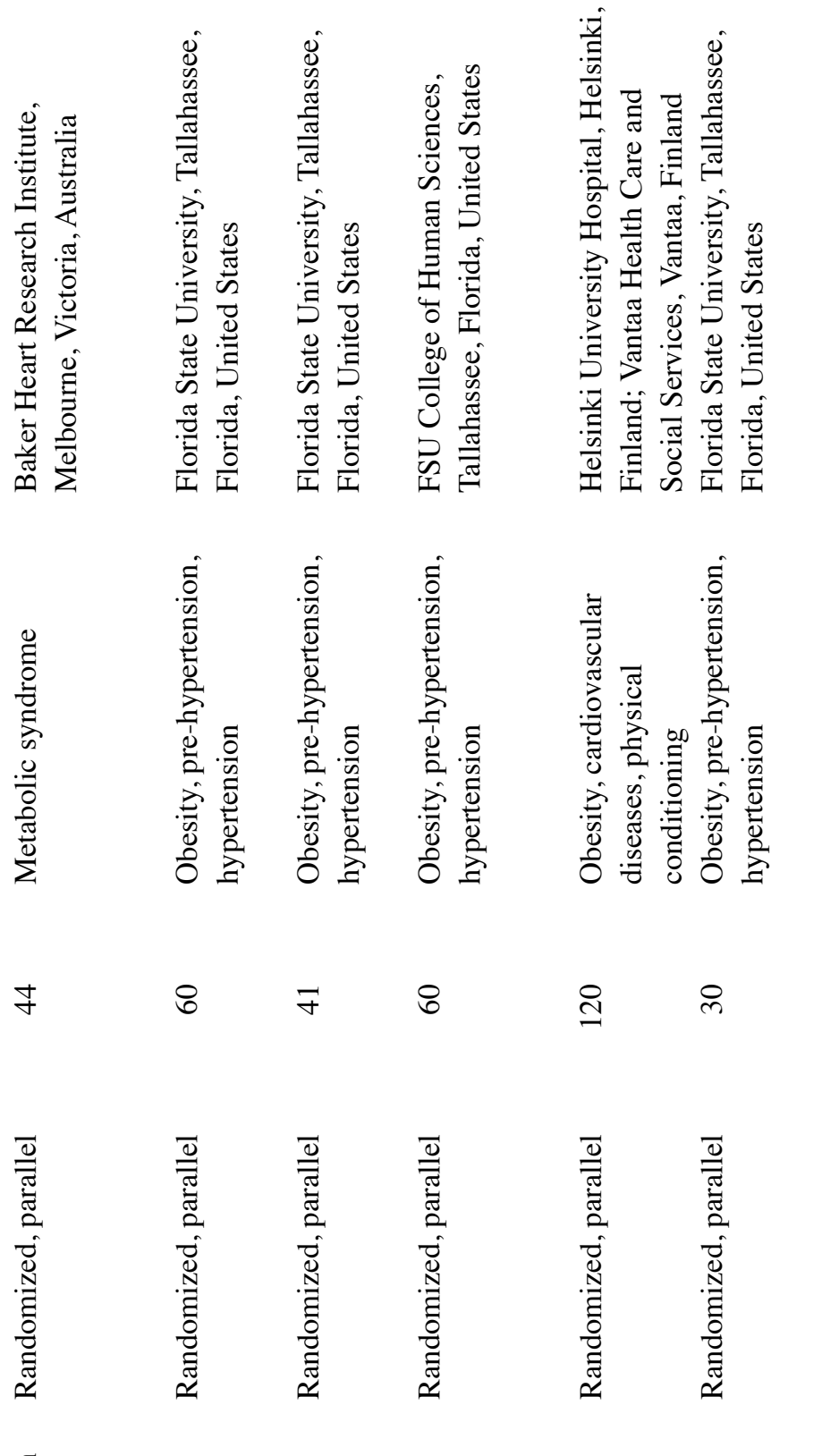

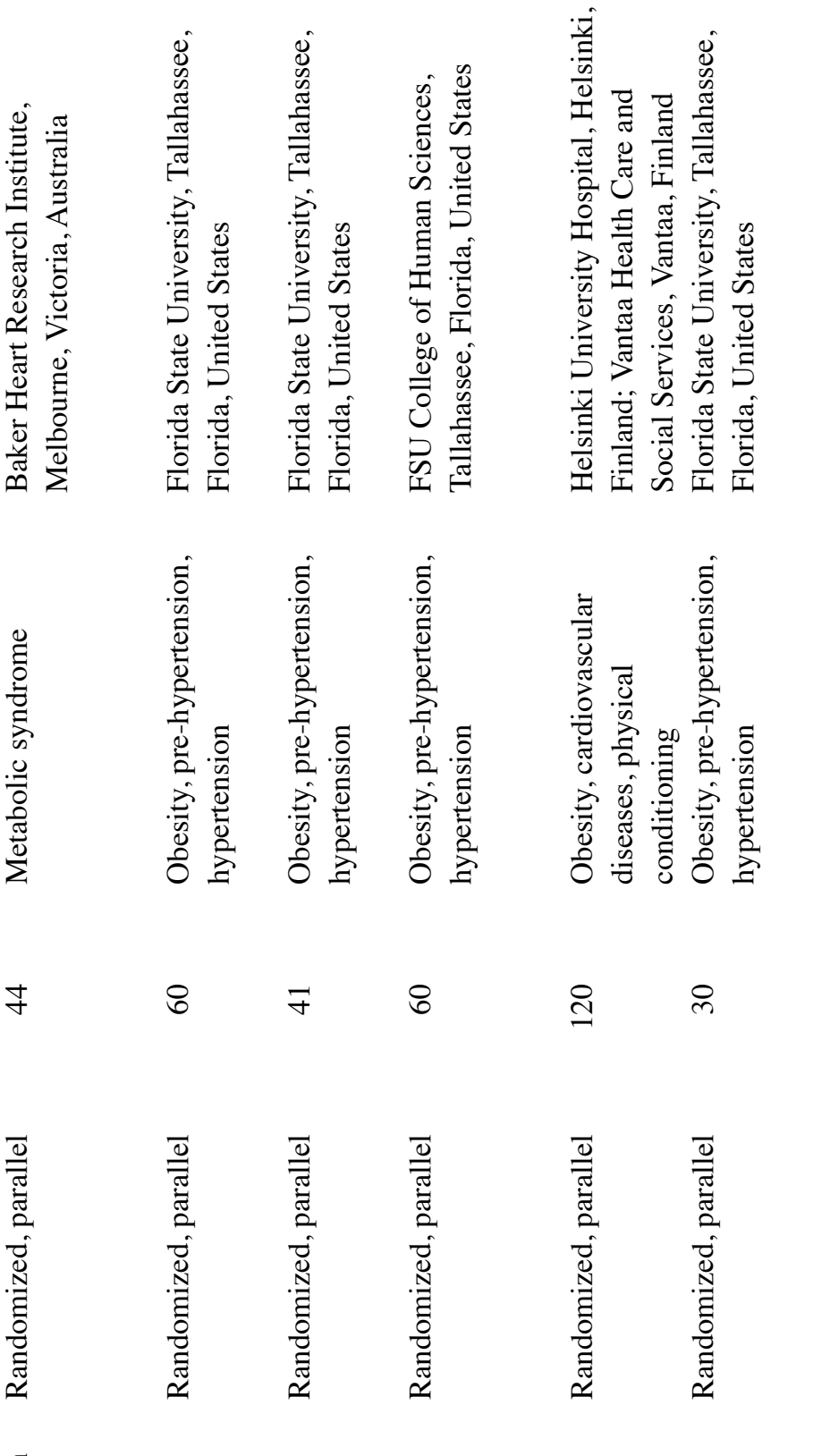

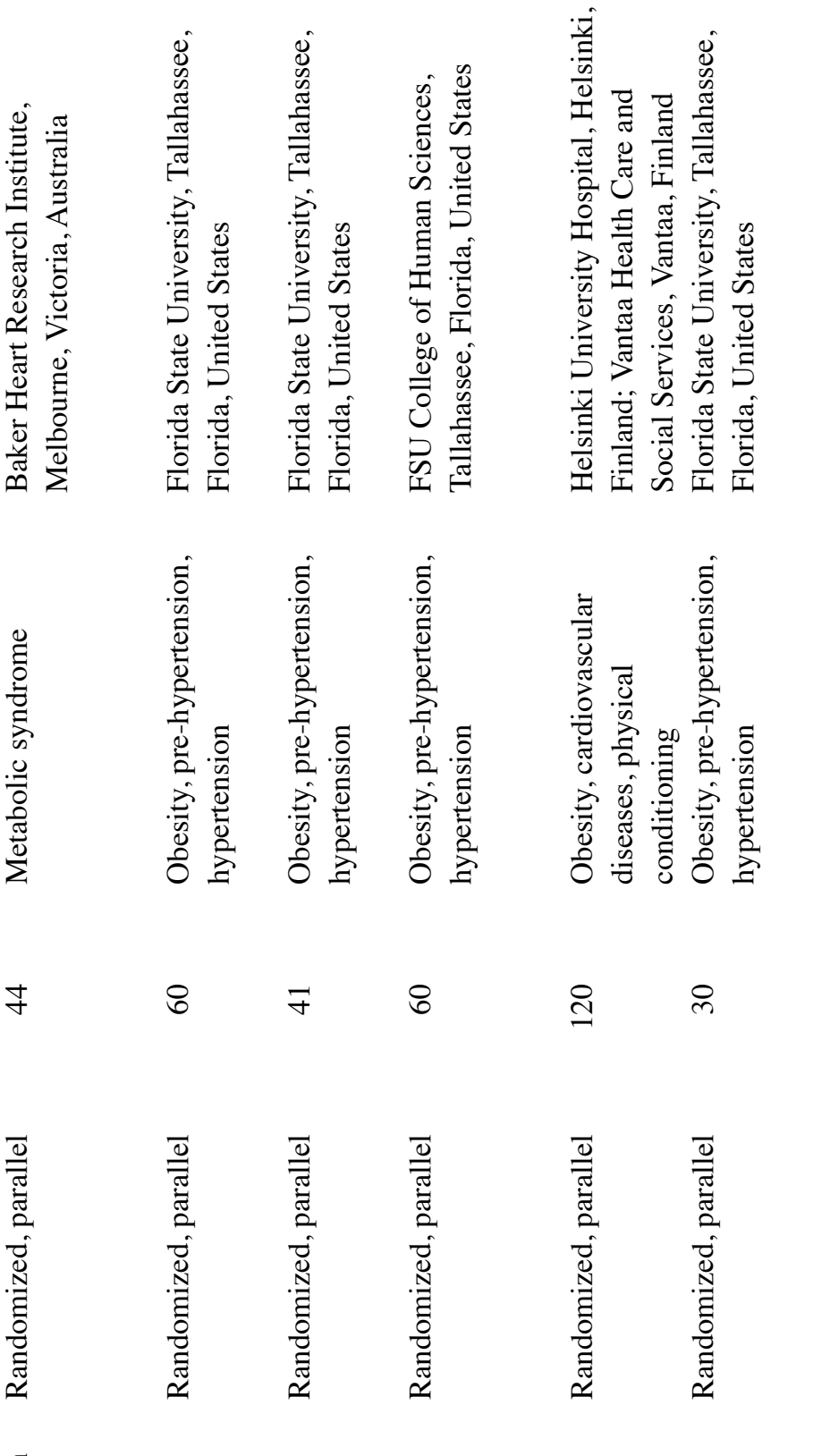
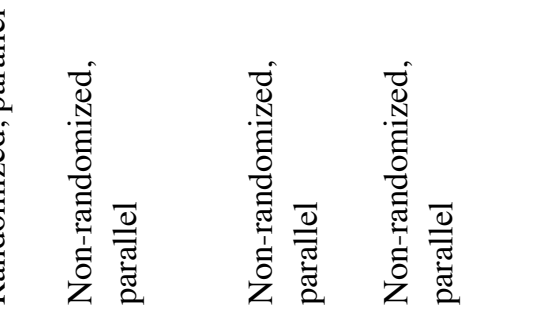

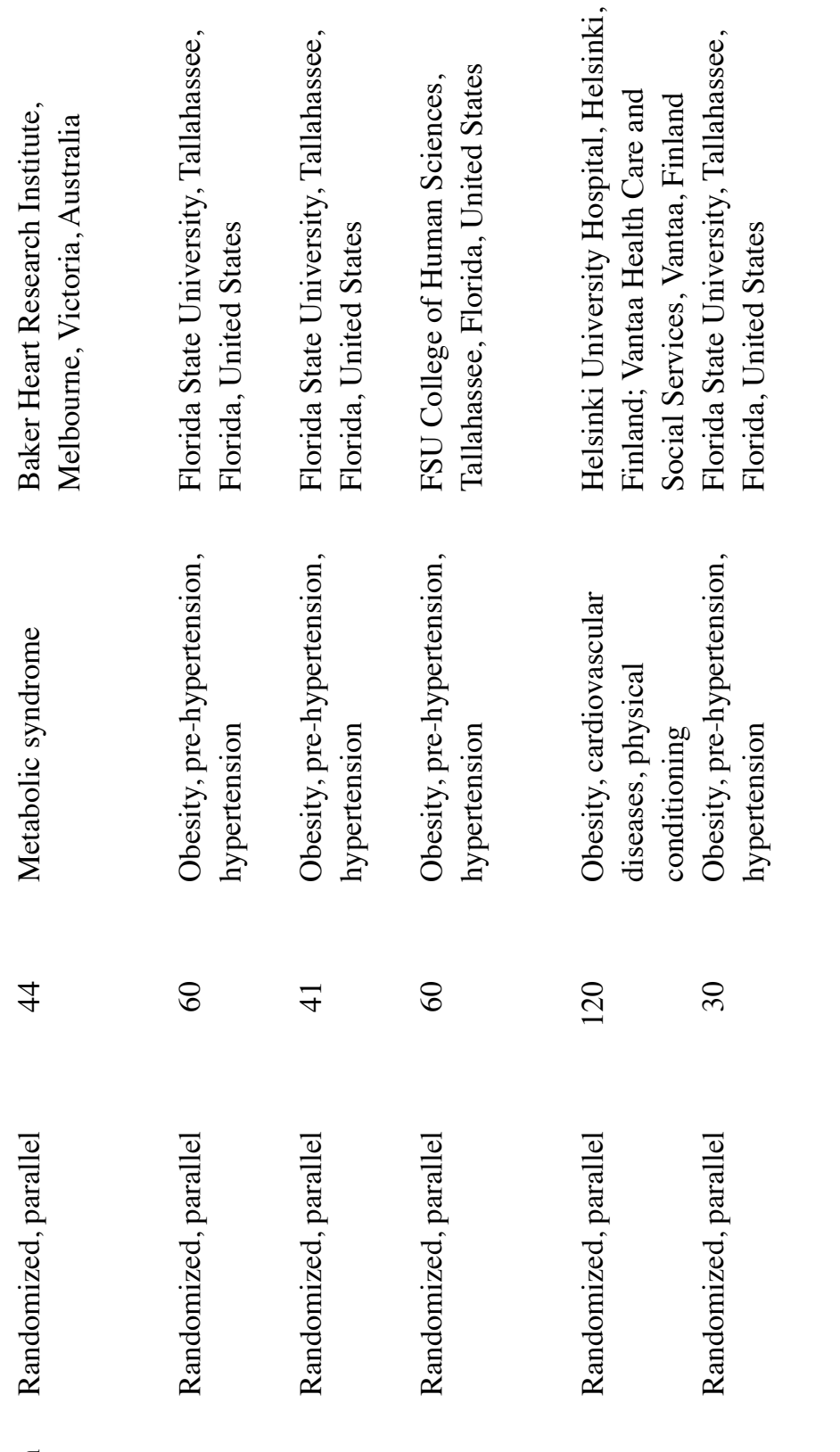

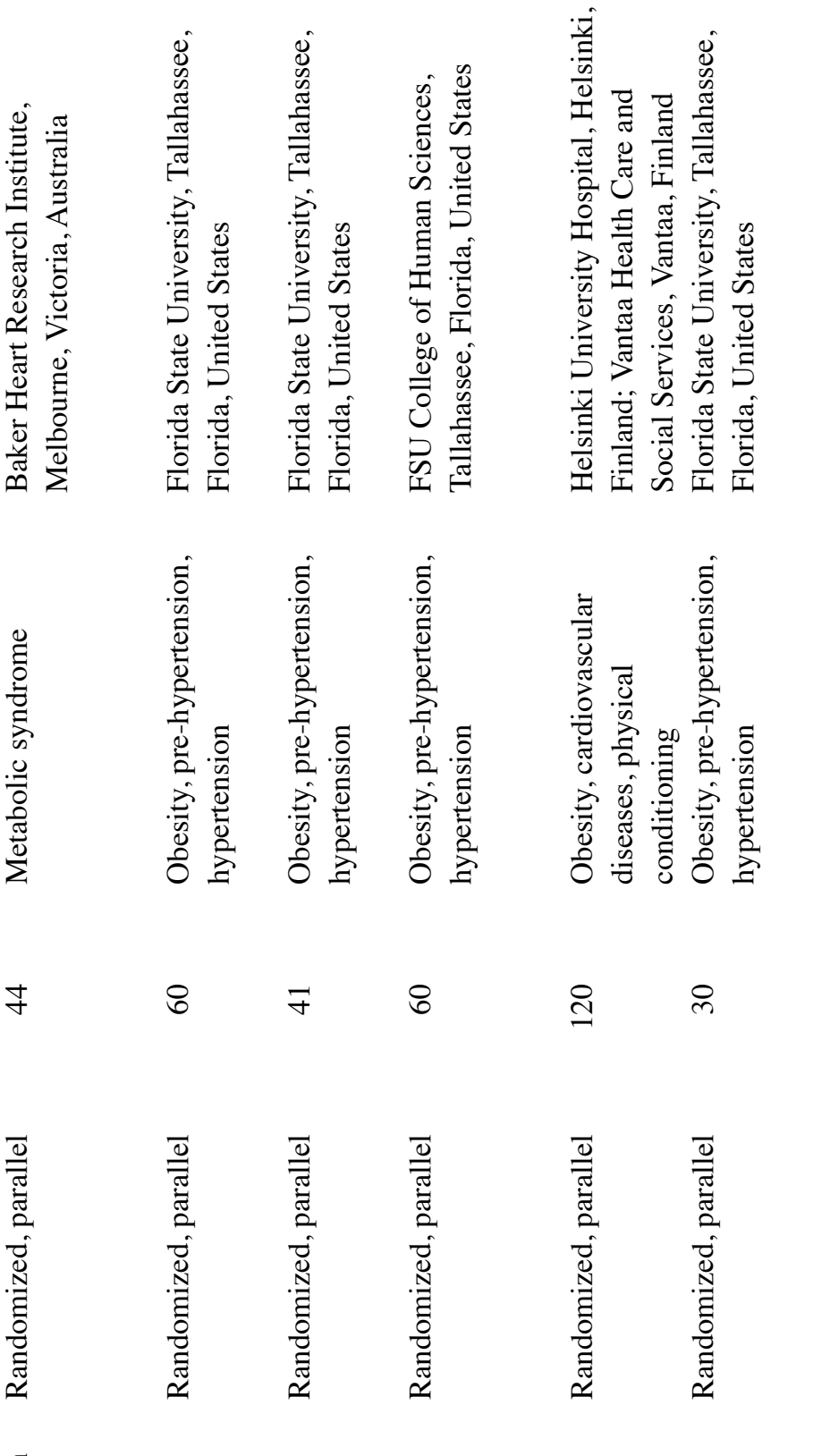

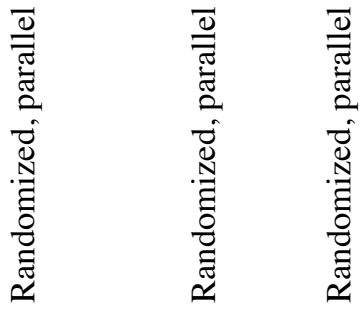

ฮี

$\stackrel{0}{\Xi}$ 
BRS and obesity were referred to as independent risk factors for hypertension in youths (53). Notably, young normotensive individuals with hypertensive parents have been shown to exhibit lower BRS compared with in those without $(57,58)$. Other studies, focusing on the interplay between gene polymorphisms and baroreflex regulation, have also found some degree of association. Notably, polymorphisms in the endothelin-A receptor, bradykinin B2 receptor, BK channel $\beta 1$ subunit, aldosterone synthase and AT1 receptor gene have been reported to be associated with decreased BRS values (59-63). In children suffering from DM (type I or II), insulin resistance also seems to serve an important role in reduced BRS compared with that in healthy children (53).

Another study in children examined the hypothesis as to whether BRS is a predictive factor for the short-term outcome of postural tachycardia syndrome (64). A total of 77 children were enrolled in the study and were followed clinically for a period of 90 days. Children with postural tachycardia syndrome exhibited significantly higher BRS compared with that in healthy individuals. Furthermore, BRS was found to be positively associated with changes in heart rate in these children (64).

\section{DM and insulin resistance}

Several studies have underlined the association between insulin resistance, hypertension, the autonomous nervous system and coronary artery disease $(3,30,32,53,65)$. A high-fat diet over an extended period of time has been reported to cause insulin resistance, autonomic dysfunction and an increase in the risk of cardiovascular disease (59). Hyperinsulinemia has also been shown to be associated with increased norepinephrine levels in patients with resistant hypertension (53).

In patients with T2DM, BRS evaluation is a tool used to assess cardiovascular autonomic neuropathy. Cassaglia et al (65) identified that the arcuate nucleus in the hypothalamus is a major insulin site of action responsible for increasing sympathetic activity and BRS. As aforementioned, BRS is important for the regulation of blood pressure and reduced BRS can result in an increase in blood pressure variability, which in turn further reduces BRS, thus creating a vicious cycle (16). Additionally, oxidative stress, which is increased in patients with obesity and insulin resistance, may have a role in lowering cardiac baroreflex activity (66-68).

Deterioration of BRS has been observed in experimental models using streptozotocin-induced DM in rats, as well as in human subjects (69). The reduced BRS in patients with DM has been linked to changes in the autonomous system and its regulation of cardiovascular function $(2,70)$. These changes may take place either at the central or peripheral levels of the baroreflex circuit and lead to dysfunction of baroreflex functionality.

Carotid atherosclerosis accompanying DM is another factor that can contribute to BRS impairment (71). The consequences of BRS deterioration in patients with DM are very important. A previous study conducted on hundreds of patients with DM or hypertension revealed that the mortality risk was almost double in patients with DM and reduced BRS compared to individuals without diabetes (72). Another study in 184 patients with DM with no apparent structural heart 
diseases identified a relationship between reduced BRS and cardiovascular incidences of congestive heart failure, myocardial infarction, stroke and cardiovascular deaths (73). Thus, in patients with DM, early diagnosis of BRS impairment may be necessary to apply effective treatment plans and slow the progression of autonomic dysfunction.

\section{Hypertension}

Obesity represents an important risk factor for hypertension, i.e. $>60 \%$ of patients with hypertension are overweight in the US (3). It has been suggested that increased weight leads to an increase in systolic blood pressure (74). Under normal conditions, the arterial baroreceptors respond to acute blood pressure changes through alterations in vascular wall stretch. Subsequently, in order to buffer these variations in blood pressure, changes in the SNA are regulated. In patients with hypertension, baroreceptors are dysfunctional and are not able to protect against the constantly elevated blood pressure (75).

In patients with obesity and hypertension, the BRS is depressed, increasing the risk for cardiac arrhythmias (69). No specific therapies are available to face this dysfunction and moreover the underlying mechanisms have not yet been fully elucidated. A previous study was performed in dogs to investigate the impact of progressive weight increase on the cardiovascular dynamic effects and also to assess baroreflex activation (76). Body weight increases resulted in a gradual elevation of arterial pressure. In order to reverse hypertension, renal denervation and baroreflex activation were used; however, the attenuation of tachycardia, and restoration of cardiac and HRV could only be effectively moderated by baroreflex activation. These findings imply that baroreflex activation therapy can reduce arterial pressure and lower the risk factors for arrhythmias (77).

Another point of interest with regard to the origin of BRS dysfunction in obesity are the kidneys. It is known that renal sympathetic activation represents an important cause of hypertension (3). Since obesity leads to activation of the renal sympathetic system, it may be hypothesized that obesity also promotes the progression of hypertension. Even though the exact mechanism is unknown, it may be associated with altered BRS, activation of the renin-angiotensin system, dysregulation of adipokines (e.g., leptin) and insulin resistance (3). A study in rats demonstrated that obesity induced an inflammatory response in the kidneys, which led to autonomic dysfunction and contributed to a decrease in baroreflex regulation (78).

\section{Physical activity}

Another issue worth mentioning that is related to obesity and BRS is the role of physical activity. The beneficial effects of exercise and training are widely known. Notably, exercise is protective against obesity, hypertension, T2DM, cardiovascular disease and depression, and promotes positive self-esteem (79). In addition, there is evidence that physical activity affects the autonomous nervous system and improves the condition of patients with autonomic disorders (72). The arterial baroreflex influences other neural reflexes in order to coordinate the autonomic adjustments to training and regulate blood pressure during exercise (80).
Individuals with hypertension can suffer significant increases in arterial pressure during physical exercise. Central command and arterial baroreflex are hypothesized to mediate the cardiovascular responses to exercise in normotensive healthy persons (81). Fukuma et al (82) enrolled patients with heart disease and studied the relationship between changes in heart rate and blood pressure increments (or decrements) in response to exercise. In accordance with Bruce's protocol, a symptom-limited treadmill exercise test was performed (83). The results revealed that BRS dysfunction in the presence of blood pressure decreases may result in insufficient capacity and activation of the sympathetic nervous system during exercise to adapt to stress.

To elucidate the possible role of sex in the relationship between training and autonomic regulation, a clinical study was performed (84). In this, blood pressure variability, BRS and autonomic modulation were examined in 14 men and 13 women. No statistically significant interactions with sex were identified. For both sexes, a profound impact of training was found on autonomic regulation, variability in blood pressure and cardiovagal BRS.

\section{Sex differences}

Differences in BRS have been observed between men and women. Generally, cardiovagal BRS after a rapid hypertensive stimulus in healthy women is less intense compared with that in men (79). However, after hypotensive stimuli, both sexes appear to exhibit similar behavior. Regarding the sympathetic BRS, there is no evident difference between men and women in young individuals; however, as age increases, the sympathetic BRS of women has been shown to decrease. This finding may be ascribed to greater arterial stiffness in women compared with in men of the same age (79). Another issue worth mentioning is the influence on muscle sympathetic neural activity of the different sex hormones levels during the menstrual cycle and pregnancy, or in response to the use of oral contraceptives (85).

The role of obesity in conjunction with sex has been investigated. Overall, as aforementioned, obesity leads to elevation of SNA, which contributes to the development of hypertension. Both BMI and WC have been reported to be associated with increased muscle sympathetic neural activity; however, these findings have only been observed in men and are not present in women with obesity $(86,87)$. Premenopausal women with obesity can suppress potentiation of the sympathetic system and hypertension due to differences in adipose tissue deposition. Possibly, vascular reactivity may also differ between the sexes (86). Females may be more sensitive to obesity-induced increases in sympathetic nerve activity and arterial pressure as they approach menopause, resulting in decreased estrogen levels and a shift of adipose tissue to the visceral area.

In addition to sex differences in adipose tissue distribution, white adipose cells in females are smaller, more lipogenic, and more insulin-sensitive due to increased insulin-induced signaling and production of lipid and glucose synthesis proteins.

A study conducted in order to compare BRS between men and women in 185 patients with T2DM revealed that women with depressed BRS exhibited a greater incidence 
of cardiovascular events compared with those with normal BRS. By contrast, no such difference was found in men (88). Another study demonstrated that women may exhibit lower values of cardiac and muscle-pump baroreflexes compared with men (89), a finding that may lead to the conclusion that older women are more vulnerable to orthostatic intolerance compared with older men.

\section{Aging}

Aging is generally related to reduced cardiovagal BRS $(22,90)$. Even though the underlying mechanism has not been clarified, it is considered that either loss of arterial distensibility and/or central intervention of the baroreflex system could be responsible for impaired BRS (91). By contrast, the sympathetic baroreflex control has not been found to be affected by age. The underlying mechanisms of decreased cardiovagal baroreflex sensitivity, may refer to factors such as increased vascular stiffening, oxidative stress and suppressed cholinergic responsiveness of the heart. This impairment of cardiovagal BRS with advanced age may result in reduced ability to buffer blood pressure changes, hypertension and a greater risk of sudden cardiac death (68). Regarding the role of sex, it has been reported that the decrease in cardiovagal BRS with age is similar between men and women (79). In pathological situations, such as DM or hypertension, women display a higher reduction than men (79).

Verma et al (89) assessed the impact of aging on muscle-pump BRS of the lateral gastrocnemius, tibialis anterior, medial gastrocnemius and soleus muscles (89). Lower cardiac BRS control was observed in the older group of patients. In another study, similar findings were found for all other muscle groups, whereas no statistically significant changes in mechanical properties were determined between young and old people, implying that age is only associated with changes in baroreflex-mediated control (79).

Differences in the connection between muscle SNA and cardiac output have also been observed. In young men, an inverse relationship has been determined between the previous two factors; however, this relationship has not been observed in older men (85). In women, there are also differences with aging; $\beta$-adrenoreceptor dilation has been shown to be attenuated with age, which results in adrenergic vasoconstriction and blood pressure increases. By contrast, sympathetic vasoconstriction is counterbalanced by adrenoreceptor-mediated vasodilation (85).

\section{Baroreflex system and bariatric surgery}

Obesity is an independent risk factor for cardiovascular disease, as it affects various inflammatory and metabolic parameters. It is associated with structural and functional cardiac alterations, leading to increased cardiac workload, systolic work stress and left ventricular hypertrophy (92). Due to the overactivity of the sympathetic nervous system, BRS can be attenuated (86). Studies have shown that if arterial compliance is reduced, then BRS is blunted $(2,73)$.

The most common types of bariatric surgery include Roux-en-Y gastric bypass (RYGB), sleeve gastrectomy (SG), biliopancreatic diversion with duodenal switch, and gastric banding, which appear to reduce morbidity and mortality and provide long-term weight loss $(93,94)$. RYGB has been proven to increase the postprandial response of the anorexigenic gut hormones glucagon-like peptide 1 (GLP-1) and peptide YY (PYY), thus leading to enhanced satiation. Significant weight loss following RYGB has been shown to be accompanied by left ventricular mass reduction, thus improving left ventricular function $(94,95)$. Notably, SG, which is a relatively newer technique, has also been associated with increased GLP-1 and PYY, and reduced ghrelin levels, which can be sustained for years after surgery $(94,95)$. In our previous study, 37 patients with morbid obesity who underwent RYGB or SG were examined before, and 3 and 6 months after surgery. BRS and HRV indices improved significantly and to the same degree after surgery in both groups; however, RYGB displayed a more beneficial effect on epicardial fat thickness and left ventricular performance compared with SG (93).

Resistant hypertension is defined as uncontrolled hypertension despite optimal doses of at least three antihypertensive medications including a diuretic, or four or more antihypertensives, and is more frequent in individuals with obesity (96). It has been reported that a weight loss of $\geq 5 \mathrm{~kg}$ can significantly decrease blood pressure and there have been several studies on the effects of bariatric surgery on hypertension. The STAMPEDE trial revealed that there was a significant reduction in the need for antihypertensive medications following bariatric surgery (97). Similarly, the GATEAWAY trial demonstrated that blood pressure was controlled with the need for less antihypertensive medications, and the improved blood pressure control was maintained 3 years after the surgery (98).

Seravalle et al (99) measured blood pressure, heart rate and BRS in hypertensive individuals with severe obesity before and after surgery. Using direct, intramural recording of SNA in the skeletal muscle it was revealed that 6 and 12 months after SG a significant improvement in baroreflex control of the sympathetic nerve system was observed, as the operation led to profound sympathoinhibitory effects, in association with reduced plasma leptin levels. Moreover, SG produced sustained decreases in muscle SNA, body weight, plasma leptin and systolic blood pressure. Thus, the authors concluded that the sympathoinhibition may be related to decreases in plasma leptin associated with a reduction in adiposity; this previous study was the first, to the best of our knowledge, to demonstrate the significant and durable sympathoinhibitory effects of bariatric surgery (99).

da Silva et al (100) conducted a study to assess the improvement of exercise capacity and peripheral metabaroreflex (expressed as the area under the curve of vascular resistance) after bariatric surgery. It was revealed that 3 months after surgery, exercise capacity was increased, whereas heart rate, blood pressure and peripheral muscular metabaroreflex were decreased (100). Furthermore, Limberg et al (101) concluded that RYGB surgery improved blood pressure reactivity due to alterations in the time course of hemodynamic responses. After surgery, patients showed an attenuation in blood pressure reactivity, and improved BRS and HRV, thus displaying a decreased cardiovascular disease risk (101). 
The effect of bariatric surgery compared with non-surgical treatment on blood pressure has been assessed in a recent review (102). According to the findings of this previous study, bariatric surgery may be considered more beneficial than non-surgical treatment in lowering blood pressure. Moreover, RYGB was revealed to have sympathoinhibitory effects due to marked reduction in plasma leptin, indicating the role of leptin in blood pressure and cardiac output of patients with obesity $(99,102)$.

\section{Conclusion}

In summary, the baroreflex represents a rapid negative feedback system the purpose of which is to buffer blood pressure variabilities. BRS represents an important homeostatic system; however, its functionality is affected by several risk factors. Obesity represents a major factor influencing baroreflex functionality, which can markedly decrease its sensitivity and lead to sympathovagal imbalance by decreasing parasympathetic activity and increasing SNA. Specifically, high abdominal visceral fat has been shown to suppress BRS. Several other factors closely related to obesity, such as DM, hypertension and cardiovascular disease, as well as other factors independent of obesity, such as aging, sex and physical activity status may affect the balance between the sympathetic and parasympathetic nervous systems. Weight loss strategies should be globally implemented in order to attenuate the increasing incidence of autonomic neuropathy.

\section{Acknowledgements}

Not applicable.

\section{Funding}

The present study was supported by the Onassis Foundation (grant no. G ZO 011-1/ 2018-2019).

\section{Availability of data and materials}

Not applicable.

\section{Author's contributions}

SKK conceived and designed the review. SKK, GA, VK, NT and AK performed the literature review. Data authentication is not applicable. All authors read and approved the final manuscript.

\section{Ethics approval and consent to participate}

Not applicable.

\section{Patient consent for publication}

Not applicable.

\section{Competing interests}

The authors declare that they have no competing interests.

\section{References}

1. Kishi T: Baroreflex failure and beat-to-beat blood pressure variation. Hypertens Res 41: 547-552, 2018.

2. Skrapari I, Tentolouris N and Katsilambros N: Baroreflex function: Determinants in healthy subjects and disturbances in diabetes, obesity and metabolic syndrome. Curr Diabetes Rev 2: 329-338, 2006.

3. Chen W, Leo S, Weng C, Yang X, Wu Y and Tang X: Mechanisms mediating renal sympathetic nerve activation in obesity-related hypertension. Herz 40 (Suppl 2): S190-S196, 2015.

4. Pinna GD, Maestri R and La Rovere MT: Assessment of baroreflex sensitivity from spontaneous oscillations of blood pressure and heart rate: Proven clinical value? Physiol Meas 36: 741-753, 2015.

5. Swenne CA: Baroreflex sensitivity: Mechanisms and measurement. Neth Heart J 21: 58-60, 2013.

6. Funakoshi K, Hosokawa K, Kishi T, Ide T and Sunagawa K: Striking volume intolerance is induced by mimicking arterial baroreflex failure in normal left ventricular function. J Card Fail 20: 53-59, 2014.

7. Mostarda C, Moraes-Silva IC, Moreira ED, Medeiros A, Piratello AC, Consolim-Colombo FM, Caldini EG, Brum PC, Krieger EM and Irigoyen MC: Baroreflex sensitivity impairment is associated with cardiac diastolic dysfunction in rats. J Card Fail 17: 519-525, 2011

8. Svitok P, Molcan L, Stebelova K, Vesela A, Sedlackova N, Ujhazy E, Mach M and Zeman M: Prenatal hypoxia in rats increased blood pressure and sympathetic drive of the adult offspring. Hypertens Res 39: 501-505, 2016.

9. Drew RC: Baroreflex and neurovascular responses to skeletal muscle mechanoreflex activation in humans: An exercise in integrative physiology. Am J Physiol Regul Integr Comp Physiol 313: R654-R659, 2017.

10. Al-Khateeb AA, Limberg JK, Barnes JN, Joyner MJ, Charkoudian N and Curry TB: Acute cyclooxygenase inhibition and baroreflex sensitivity in lean and obese adults. Clin Auton Res 27: 17-23, 2017.

11. Pankova NB, Alchinova IB, Cherepov AB, Yakovenko EN and Karganov MY: Cardiovascular system parameters in participants of Arctic expeditions. Int J Occup Med Environ Health 33: 819-828, 2020.

12. Javorka M, Lazarova Z, Tonhajzerova I, Turianikova Z, Honzikova N, Fiser B, Javorka K and Baumert M: Baroreflex analysis in diabetes mellitus: Linear and nonlinear approaches. Med Biol Eng Comput 49: 279-288, 2011.

13. Vinik AI and Ziegler D: Diabetic cardiovascular autonomic neuropathy. Circulation 115: 387-397, 2007.

14. Pinheiro A, Vianna LC and Carmo JC: Noiseless variable-pressure neck chamber device to assess the carotid baroreflex function. Front Physiol 11: 613311, 2021.

15. Taylor CE, Willie CK, Ainslie PN and Tzeng YC: Assessment of human baroreflex function using carotid ultrasonography: What have we learnt? Acta Physiol (Oxf) 211: 297-313, 2014.

16. Sakamoto M, Matsutani D and Kayama Y: Clinical implications of baroreflex sensitivity in type 2 diabetes. Int Heart J 60: 241-246, 2019.

17. Indumathy J, Pal GK, Pal P, Ananthanarayanan PH, Parija SC, Balachander J and Dutta TK: Decreased baroreflex sensitivity is linked to sympathovagal imbalance, body fat mass and altered cardiometabolic profile in pre-obesity and obesity. Metabolism 64: 1704-1714, 2015.

18. Li CH, Sun ZJ, Lu FH, Chou YT, Yang YC, Chang CJ and Wu JS: Epidemiological evidence of increased waist circumference, but not body mass index, associated with impaired baroreflex sensitivity. Obes Res Clin Pract 14: 158-163, 2020.

19. Toschi-Dias E, Trombetta IC, Silva VJD, Maki-Nunes C, Cepeda FX, Alves MJNN, Carvalho GL, Drager LF, Lorenzi-Filho G, Negrão CE and Rondon M: Diet associated with exercise improves baroreflex control of sympathetic nerve activity in metabolic syndrome and sleep apnea patients. Sleep Breath 23: 143-151, 2019.

20. Takahashi N, Anan F, Nakagawa M, Yufu K, Shinohara T, Tsubone T, Goto K, Masaki T, Katsuragi I, Tanaka K, et al: Hypoadiponectinemia in type 2 diabetes mellitus in men is associated with sympathetic overactivity as evaluated by cardiac 123I-metaiodobenzylguanidine scintigraphy. Metabolism 56: 919-924, 2007. 
21. Pierce GL, Harris SA, Seals DR, Casey DP, Barlow PB and Stauss HM: Estimated aortic stiffness is independently associated with cardiac baroreflex sensitivity in humans: Role of ageing and habitual endurance exercise. J Hum Hypertens 30: 513-520, 2016.

22. Serhiyenko VA and Serhiyenko AA: Cardiac autonomic neuropathy: Risk factors, diagnosis and treatment. World J Diabetes 9: $1-24,2018$

23. Milovanovic B, Trifunovic D and Djuric D: Autonomic nervous system adjustment (ANSA) in patients with hypertension treated with enalapril. Acta Physiol Hung 98: 71-84, 2011.

24. Mengal V, Silva PH, Tiradentes RV, Santuzzi CH, de Almeida SA, Sena GC, Bissoli NS, Abreu GR and Gouvea SA: Aliskiren and l-arginine treatments restore depressed baroreflex sensitivity and decrease oxidative stress in renovascular hypertension rats. Hypertens Res 39: 769-776, 2016.

25. Saku K, Kishi T, Sakamoto K, Hosokawa K, Sakamoto T, Murayama Y, Kakino T, Ikeda M, Ide T and Sunagawa K: Afferent vagal nerve stimulation resets baroreflex neural arc and inhibits sympathetic nerve activity. Physiol Rep 2: e12136, 2014.

26. Seravalle G and Grassi G: Sympathetic nervous system, hypertension, obesity and metabolic syndrome. High Blood Press Cardiovasc Prev 23: 175-179, 2016.

27. Tentolouris N, Argyrakopoulou G and Katsilambros N: Perturbed autonomic nervous system function in metabolic syndrome. Neuromolecular Med 10: 169-178, 2008.

28. Guarino D, Nannipieri M, Iervasi G, Taddei S and Bruno RM: The role of the autonomic nervous system in the pathophysiology of obesity. Front Physiol 8: 665, 2017.

29. Russo B, Menduni M, Borboni P, Picconi F and Frontoni S: Autonomic nervous system in obesity and insulin-resistance-the complex interplay between leptin and central nervous system. Int J Mol Sci 22: 5187, 2021.

30. Man T, Tegegne BS, van Roon AM, Rosmalen JGM, Nolte IM, Snieder H and Riese H: Spontaneous baroreflex sensitivity and its association with age, sex, obesity indices and hypertension: A population study. Am J Hypertens 2021(Epub ahead of print).

31. European Society of Hypertension-European Society of Cardiology Guidelines Committee: 2003 European Society of Hypertension-European Society of Cardiology guidelines for the management of arterial hypertension. J Hypertens 21: 1011-1053, 2003.

32. Thorp AA and Schlaich MP: Relevance of sympathetic nervous system activation in obesity and metabolic syndrome. J Diabetes Res 2015: 341583, 2015.

33. Myers MG, Cowley MA and Münzberg H: Mechanisms of leptin action and leptin resistance. Annu Rev Physiol 70: 537-556, 2008

34. Ciriello J: Leptin in nucleus of the solitary tract alters the cardiovascular responses to aortic baroreceptor activation. Peptides 44: 1-7, 2013.

35. Fantin F, Giani A, Zoico E, Rossi AP, Mazzali G and Zamboni M: Weight loss and hypertension in obese subjects. Nutrients 11: $1667,2019$.

36. Lakkis JI and Weir MR: Obesity and kidney disease. Prog Cardiovasc Dis 61: 157-167, 2018.

37. Abboud FM and Singh MV: Autonomic regulation of the immune system in cardiovascular diseases. Adv Physiol Educ 41: 578-593, 2017.

38. Lumeng $\mathrm{CN}$ and Saltiel AR: Inflammatory links between obesity and metabolic disease. J Clin Invest 121: 2111-2117, 2011.

39. Pal GK, Adithan C, Ananthanarayanan PH, Pal P, Nanda N, Thiyagarajan D, Syamsunderkiran AN, Lalitha V and Dutta TK: Association of sympathovagal imbalance with cardiovascular risks in young prehypertensives. Am J Cardiol 112: 1757-1762, 2013.

40. Engin A: The definition and prevalence of obesity and metabolic syndrome. Adv Exp Med Biol 960: 1-17, 2017.

41. McCracken E, Monaghan M and Sreenivasan S: Pathophysiology of the metabolic syndrome. Clin Dermatol 36: 14-20, 2018.

42. Koren D and Taveras EM: Association of sleep disturbances with obesity, insulin resistance and the metabolic syndrome. Metabolism 84: 67-75, 2018.

43. Dieli-Conwright CM, Courneya KS, Demark-Wahnefried W, Sami N, Lee K, Buchanan TA, Spicer DV, Tripathy D, Bernstein L and Mortimer JE: Effects of aerobic and resistance exercise on metabolic syndrome, sarcopenic obesity, and circulating biomarkers in overweight or obese survivors of breast cancer: A randomized controlled trial. J Clin Oncol 36: $875-883,2018$.
44. Demidowich AP, Levine JA, Apps R, Cheung FK, Chen J, Fantoni G; CHI Consortium, Patel TP and Yanovski JA: Colchicine's effects on metabolic and inflammatory molecules in adults with obesity and metabolic syndrome: Results from a pilot randomized controlled trial. Int J Obes (Lond) 44: 1793-1799, 2020.

45. Jais A and Brüning JC: Hypothalamic inflammation in obesity and metabolic disease. J Clin Invest 127: 24-32, 2017.

46. Rubio-Ruiz ME, Guarner-Lans V, Pérez-Torres I and Soto ME Mechanisms underlying metabolic syndrome-related sarcopenia and possible therapeutic measures. Int J Mol Sci 20: 647, 2019.

47. Alberti KG, Eckel RH, Grundy SM, Zimmet PZ, Cleeman JI, Donato KA, Fruchart JC, James WP, Loria CM and Smith SC Jr: International Diabetes Federation Task Force on Epidemiology and Prevention; Hational Heart, Lung, and Blood Institute American Heart Association; World Heart Federation; International Atherosclerosis Society; International Association For The Study of Obesity: Harmonizing the metabolic syndrome: A joint interim statement of the international diabetes federation task force on epidemiology and prevention; national heart lung, and blood institute; American Heart Association; World Heart Federation; International Atherosclerosis Society; and International Association for the Study of Obesity. Circulation 120: 1640-1645, 2009.

48. Quarti Trevano F, Dell'Oro R, Biffi A, Seravalle G, Corrao G, Mancia G and Grassi G: Sympathetic overdrive in the metabolic syndrome: Meta-analysis of published studies. J Hypertens 38: $565-572,2020$

49. Grassi G, Dell'Oro R, Quarti-Trevano F, Scopelliti F, Seravalle G, Paleari F, Gamba PL and Mancia G: Neuroadrenergic and reflex abnormalities in patients with metabolic syndrome. Diabetologia 48: 1359-1365, 2005.

50. Grassi G, Facchini A, Trevano FQ, Dell'Oro R, Arenare F, Tana F, Bolla GB, Monzani A, Robuschi M and Mancia G: Obstructive sleep apnea-dependent and -independent adrenergic activation in obesity. Hypertension 46: 321-325, 2005.

51. Zanoli L, Empana JP, Estrugo N, Escriou G, Ketthab H, Pruny JF, Castellino P, Laude D, Thomas F, Pannier B, et al: The neural baroreflex pathway in subjects with metabolic syndrome: A sub-study of the paris prospective study III. Medicine (Baltimore) 95: e2472, 2016.

52. Zhang LL, Zhang Y, Cheng YQ, Zhang JM, Liu HQ, Wang WZ, Mehta JL, Xiong ZG, Su DF and Liu AJ: Metabolic syndrome emerges after artificial selection for low baroreflex sensitivity. CNS Neurosci Ther 24: 828-836, 2018.

53. Honzíková $\mathrm{N}$ and Závodná E: Baroreflex sensitivity in children and adolescents: Physiology, hypertension, obesity, diabetes mellitus. Physiol Res 65: 879-889, 2016.

54. Lazarova Z, Tonhajzerova I, Trunkvalterova Z, Brozmanova A, Honzíková N, Javorka K, Baumert M and Javorka M: Baroreflex sensitivity is reduced in obese normotensive children and adolescents. Can J Physiol Pharmacol 87: 565-571, 2009.

55. Javorka M, Tonhajzerova I, Turianikova Z, Czippelova B and Chladekova L: Causal baroreflex sensitivity analysis in obese children and adolescents. Can J Diabetes 37: S285, 2013.

56. Honzíková N, Nováková Z, Závodná E, Paderová J, Lokaj P, Fiser B, Balcárková $\mathrm{P}$ and Hrstková $\mathrm{H}$ : Baroreflex sensitivity in children, adolescents, and young adults with essential and white-coat hypertension. Klin Padiatr 218: 237-242, 2006

57. Parmer RJ, Cervenka JH and Stone RA: Baroreflex sensitivity and heredity in essential hypertension. Circulation 85: 497-503, 1992.

58. Lopes HF, Silva HB, Consolim-Colombo FM, Barreto Filho JA, Riccio GM, Giorgi DM and Krieger EM: Autonomic abnormalities demonstrable in young normotensive subjects who are children of hypertensive parents. Braz J Med Biol Res 33: 51-54, 2000.

59. Ormezzano O, Poirier O, Mallion JM, Nicaud V, Amar J, Chamontin B, Mounier-Véhier C, François P, Cambien F and Baguet JP: A polymorphism in the endothelin-A receptor gene is linked to baroreflex sensitivity. J Hypertens 23: 2019-2026, 2005.

60. Xing-Sheng Y, Yong-Zhi L, Jie-Xin L, Yu-Qing G, Zhang-Huang $\mathrm{C}$, Chong-Fa Z, Zhi-Zhong $\mathrm{T}$ and Shu-Zheng L: Genetic influence on baroreflex sensitivity in normotensive young men. Am J Hypertens 23: 655-659, 2010.

61. Gollasch M, Tank J, Luft FC, Jordan J, Maass P, Krasko C, Sharma AM, Busjahn A and Bähring S: The BK channel betal subunit gene is associated with human baroreflex and blood pressure regulation. J Hypertens 20: 927-933, 2002. 
62. Ylitalo A, Airaksinen KE, Hautanen A, Kupari M, Carson M, Virolainen J, Savolainen M, Kauma H, Kesäniemi YA, White PC and Huikuri HV: Baroreflex sensitivity and variants of the renin angiotensin system genes. J Am Coll Cardiol 35: 194-200, 2000.

63. Jíra M, Závodná E, Honzíková N, Nováková Z, Vašků A, Izakovicová Hollá L and Fiser B: Association of A1166C polymorphism in AT(1) receptor gene with baroreflex sensitivity. Physiol Res 59: 517-528, 2010.

64. Li H, Liao Y, Wang Y, Liu P, Sun C, Chen Y, Tang C, Jin H and $\mathrm{Du} \mathrm{J}$ : Baroreflex sensitivity predicts short-term outcome of postural tachycardia syndrome in children. PLoS One 11: e0167525, 2016.

65. Cassaglia PA, Hermes SM, Aicher SA and Brooks VL: Insulin acts in the arcuate nucleus to increase lumbar sympathetic nerve activity and baroreflex function in rats. J Physiol 589: 1643-1662, 2011

66. Pan Y, Rong Y, Huang J, Zhu K, Chen J, Yu C and Chen M: Lower cardiovagal tone and baroreflex sensitivity associated with hepatic insulin resistance and promote cardiovascular disorders in Tibetan minipigs induced by a high fat and high cholesterol diet. J Diabetes Complications 33: 278-288, 2019.

67. Lucini D, Cusumano G, Bellia A, Kozakova M, Difede G Lauro R and Pagani M; Linosa Study Group: Is reduced baroreflex gain a component of the metabolic syndrome? Insights from the LINOSA study. J Hypertens 24: 361-370, 2006

68. Hendricks AS, Lawson MJ, Figueroa JP, Chappell MC, Diz DI and Shaltout HA: Central ANG-(1-7) infusion improves blood pressure regulation in antenatal betamethasone-exposed sheep and reveals sex-dependent effects on oxidative stress. Am J Physiol Heart Circ Physiol 316: H1458-H1467, 2019.

69. Rowaiye OO, Jankowska EA and Ponikowska B: Baroreceptor sensitivity and diabetes mellitus. Cardiol J 20: 453-463, 2013.

70. Kück JL, Bönhof GJ, Strom A, Zaharia OP, Müssig K, Szendroedi J, Roden M and Ziegler D: Impairment in baroreflex sensitivity in recent-onset type 2 diabetes without progression over 5 years. Diabetes 69: 1011-1019, 2020.

71. Yakhou L, Constant I, Merle JC, Laude D, Becquemin JP and Duvaldestin P: Noninvasive investigation of autonomic activity after carotid stenting or carotid endarterectomy. J Vasc Surg 44: 472-479, 2006

72. Gerritsen J, Dekker JM, TenVoorde BJ, Kostense PJ, Heine RJ, Bouter LM, Heethaar RM and Stehouwer CD: Impaired autonomic function is associated with increased mortality, especially in subjects with diabetes, hypertension, or a history of cardiovascular disease: The Hoorn Study. Diabetes Care 24: 1793-1798, 2001

73. Okada N, Takahashi N, Yufu K, Murozono Y, Wakisaka O, Shinohara T, Anan F, Nakagawa M, Hara M, Saikawa T and Yoshimatsu H: Baroreflex sensitivity predicts cardiovascular events in patients with type 2 diabetes mellitus without structura heart disease. Circ J 74: 1379-1383, 2010.

74. Ozemek C, Tiwari S, Sabbahi A, Carbone S and Lavie CJ: Impact of therapeutic lifestyle changes in resistant hypertension. Prog Cardiovasc Dis 63: 4-9, 2020.

75. Guyenet PG, Stornetta RL, Souza GMPR, Abbott SBG and Brooks VL: Neuronal networks in hypertension: Recent advances. Hypertension 76: 300-311, 2020.

76. Iliescu R, Tudorancea I, Irwin ED and Lohmeier TE: Chronic baroreflex activation restores spontaneous baroreflex control and variability of heart rate in obesity-induced hypertension. Am J Physiol Heart Circ Physiol 305: H1080-H1088, 2013.

77. Alnima T, Kroon AA and de Leeuw PW: Baroreflex activation therapy for patients with drug-resistant hypertension. Expert Rev Cardiovasc Ther 12: 955-962, 2014.

78. Khan SA, Sattar MZA, Abdullah NA, Rathore HA, Ahmad A, Abdulla MH and Johns EJ: Improvement in baroreflex control of renal sympathetic nerve activity in obese Sprague Dawley rats following immunosuppression. Acta Physiol (Oxf) 221: 250-265, 2017.

79. Fu Q and Ogoh S: Sex differences in baroreflex function in health and disease. J Physiol Sci 69: 851-859, 2019.

80. Raven PB, Young BE and Fadel PJ: Arterial baroreflex resetting during exercise in humans: Underlying signaling mechanisms. Exerc Sport Sci Rev 47: 129-141, 2019.

81. Dombrowski M, Mannozzi J and O'Leary DS: Neural control of cardiovascular function during exercise in hypertension. Front Physiol 9: 1829, 2018

82. Fukuma N, Kato K, Munakata K, Hayashi H, Kato Y, Aisu N, Takahashi H, Mabuchi K and Mizuno K: Baroreflex mechanisms and response to exercise in patients with heart disease. Clin Physiol Funct Imaging 32: 305-309, 2012.
83. Hamlin MJ, Draper N, Blackwell G, Shearman JP and Kimber NE: Determination of maximal oxygen uptake using the bruce or a novel athlete-led protocol in a mixed population. J Hum Kinet 31: 97-104, 2012.

84. Kingsley JD, Tai YL, Marshall EM, Glasgow A, Oliveira R, Parks JC and Mayo X: Autonomic modulation and baroreflex sensitivity after acute resistance exercise: Responses between sexes. J Sports Med Phys Fitness 59: 1036-1044, 2019.

85. Baker SE, Limberg JK, Ranadive SM and Joyner MJ Neurovascular control of blood pressure is influenced by aging, sex, and sex hormones. Am J Physiol Regul Integr Comp Physiol 311: R1271-R1275, 2016.

86. Brooks VL, Shi Z, Holwerda SW and Fadel PJ: Obesity-induced increases in sympathetic nerve activity: Sex matters. Auton Neurosci 187: 18-26, 2015.

87. Straznicky NE, Grima MT, Sari CI, Eikelis N, Nestel PJ, Dixon JB, Lambert GW, Schlaich MP, Phillips SE and Lambert EA: Neck circumference is associated with muscle sympathetic nerve activity in overweight and obese men but not women. Front Physiol 8: 203, 2017.

88. Yufu K, Takahashi N, Okada N, Wakisaka O, Shinohara T, Nakagawa M, Hara M, Yoshimatsu H and Saikawa T: Gender difference in baroreflex sensitivity to predict cardiac and cerebrovascular events in type 2 diabetic patients. Circ J 75: 1418-1423, 2011

89. Verma AK, Xu D, Garg A, Blaber AP and Tavakolian K: Effect of aging on muscle-pump baroreflex of individual leg muscles during standing. front Physiol 10: 845, 2019.

90. Monahan KD: Effect of aging on baroreflex function in humans. Am J Physiol Regul Integr Comp Physiol 293: R3-R12, 2007.

91. Bonyhay I, Jokkel G and Kollai M: Relation between baroreflex sensitivity and carotid artery elasticity in healthy humans. Am J Physiol 271: H1139-H1144, 1996.

92. Nakamura M and Sadoshima J: Cardiomyopathy in obesity, insulin resistance and diabetes. J Physiol 598: 2977-2993, 2020.

93. Kokkinos A, Alexiadou K, Liaskos C, Argyrakopoulou G, Balla I, Tentolouris N, Moyssakis I, Katsilambros N, Vafiadis I, Alexandrou A and Diamantis T: Improvement in cardiovascular indices after Roux-en-Y gastric bypass or sleeve gastrectomy for morbid obesity. Obes Surg 23: 31-38, 2013

94. Koshino Y, Villarraga HR, Somers VK, Miranda WR, Garza CA Hsiao JF, Yu Y, Saleh HK and Lopez-Jimenez F: Changes in myocardial mechanics in patients with obesity following major weight loss after bariatric surgery. Obesity (Silver Spring) 21: 1111-1118, 2013.

95. Lakhani M and Fein S: Effects of obesity and subsequent weight reduction on left ventricular function. Cardiol Rev 19: 1-4, 2011

96. Schiavon CA, Pio-Abreu A and Drager LF: Bariatric surgery for resistant hypertension: Working in progress! Curr Hypertens Rep 22: 55, 2020

97. Schauer PR, Bhatt DL, Kirwan JP, Wolski K, Aminian A, Brethauer SA, Navaneethan SD, Singh RP, Pothier CE, Nissen SE, et al: Bariatric surgery versus intensive medical therapy for diabetes - 5-year outcomes. N Engl J Med 376: 641-651, 2017.

98. Schiavon CA, Bersch-Ferreira AC, Santucci EV, Oliveira JD, Torreglosa CR, Bueno PT, Frayha JC, Santos RN, Damiani LP, Noujaim PM, et al: Effects of bariatric surgery in obese patients with hypertension: The GATEWAY randomized trial (Gastric Bypass to Treat Obese Patients with Steady Hypertension). Circulation 137: 1132-1142, 2018.

99. Seravalle G, Colombo M, Perego P, Giardini V, Volpe M, Dell'Oro R, Mancia G and Grassi G: Long-term sympathoinhibitory effects of surgically induced weight loss in severe obese patients. Hypertension 64: 431-437, 2014.

100. da Silva RP, Martinez D, Faria CC, de Carli LA, de Souza WI, Meinhardt NG, Souto KE, Trindade MR and Ribeiro JP: Improvement of exercise capacity and peripheral metaboreflex after bariatric surgery. Obes Surg 23: 1835-1841, 2013.

101. Limberg JK, Guo W, Joyner MJ, Charkoudian N and Curry TB: Early blood pressure response to isometric exercise is attenuated in obese individuals who have undergone bariatric surgery. J Appl Physiol (1985) 124: 960-969, 2018.

102. Wang L, Lin M, Yu J, Fan Z, Zhang S, Lin Y, Chen X and Peng F: The impact of bariatric surgery versus non-surgical treatment on blood pressure: Systematic review and meta-analysis. Obes Surg 31: 4970-4984, 2021.

This work is licensed under a Creative Commons Attribution-NonCommercial-NoDerivatives 4.0 International (CC BY-NC-ND 4.0) License. 